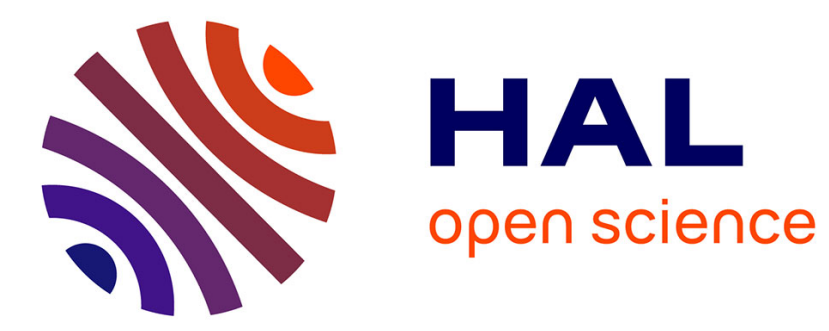

\title{
Design Thinking for Pre-empting Digital Disruption
}

\author{
Aurona Gerber, Machdel Matthee
}

\section{To cite this version:}

Aurona Gerber, Machdel Matthee. Design Thinking for Pre-empting Digital Disruption. 18th Conference on e-Business, e-Services and e-Society (I3E), Sep 2019, Trondheim, Norway. pp.759-770, 10.1007/978-3-030-29374-1_62. hal-02510158

\section{HAL Id: hal-02510158 \\ https://hal.inria.fr/hal-02510158}

Submitted on 17 Mar 2020

HAL is a multi-disciplinary open access archive for the deposit and dissemination of scientific research documents, whether they are published or not. The documents may come from teaching and research institutions in France or abroad, or from public or private research centers.
L'archive ouverte pluridisciplinaire HAL, est destinée au dépôt et à la diffusion de documents scientifiques de niveau recherche, publiés ou non, émanant des établissements d'enseignement et de recherche français ou étrangers, des laboratoires publics ou privés. 


\title{
Design Thinking for Pre-empting Digital Disruption
}

\author{
Aurona Gerber ${ }^{1[0000-0003-1743-8167]}$ and Machdel Matthee ${ }^{1[0000-0002-6973-1798]}$ \\ ${ }^{1}$ Department of Informatics, University of Pretoria, Pretoria, South Africa \\ aurona.gerber@up.ac.za
}

\begin{abstract}
Digital disruption is the phenomenon when established businesses succumb to new business models that exploit emerging technologies. Futurists often make dire predictions when discussing the impact of digital disruption, for instance that $40 \%$ of the Fortune 500 companies will disappear within the next decade. The digital disruption phenomenon was already studied two decades ago when Clayton Christensen developed a Theory of Disruptive Innovation, which is a popular theory for describing and explaining disruption due to technology developments that had occurred in the past. However it is still problematic to understand what is necessary to avoid disruption, especially within the context of a sustainable society in the $21^{\text {st }}$ century. A key aspect we identified is the behavior of non-mainstream customers of an emerging technology, which is difficult to predict, especially when an organization is operating in an existing solution space. In this position paper we propose complementing the Theory of Disruptive Innovation with design thinking in order to identify the performance attributes that encourage the unpredictable and unforeseen customer behavior that is a cause for disruption. We employ case-based scenario analysis of higher education as evaluation mechanism for our extended disruptive innovation theory. Our position is that a better understanding of the implicit and unpredictable customer behavior that cause disruption due to additional performance attributes (using design thinking) could assist organizations to pre-empt digital disruption and adapt to support the additional functionality.
\end{abstract}

Keywords: Digital Disruption, Design Thinking, Theory of Disruptive Innovation

\section{$1 \quad$ Introduction}

Digital disruption was coined in the early 1980 to describe the phenomenon of failed companies such as Kodak that unexpectedly failed due to digitization and emerging technologies. The irony of this specific case is that Kodak developed the first digital camera that digitized photography but failed to capitalize on the technology that lead to their eventual closing down [1]. A similar case is that of the SmithCorona typewriter company that was established in 1886 [2]. Smith-Corona was well positioned as a typewriter technology leader during the eighties when personal computers were introduced, for instance, introducing a cartridge ribbon in 1973 that eliminated the annoying problem of ink-stained fingers when replacing the inked ribbon [2]. Smith-Corona failed to capitalize on the developments in word processing and 
viewed the personal computer market as a rival technology that they could counter with continued improvements in typewriter technology. This strategy lead to their demise about 20 years later when they were bought over by a private company during their second bankruptcy and ceased manufacturing of all typewriters [2].

The cases described are of companies that were large, well-managed and well positioned as technological leaders, however, they became victims of technological developments that created new customer bases and eroded their market share. This phenomenon was named in the 90's by Bower and Christensen in Disruptive Technologies: Catching the Wave [3] and The Innovator's Dilemma [4]. The original work subsequently developed into the Theory of Disruptive Innovation (TDI), which still remains one of the most significant theories regarding disruption two decades later [4, 5]. A key observation of DTI is that companies focus on their most-demanding mainstream customers as their most important sources of revenue, and this cause them to ignore emerging technologies ${ }^{1}$ due to relative performance that does not satisfy the needs of these mainstream customers [3]. Mainstream customers demand better performance and therefore often oppose emerging innovations in favour of developments in existing technologies. In addition, company structures are built to support profit value networks and eliminate risk, and such value networks disregard emerging innovations representing risk and low profits. In the case of Kodak, digital photos could not match the quality of chemically developed photos for a while. In the case of Smith-Corona, large companies had typist pools with typists extremely capable on manual typewriters who regarded word processors as cumbersome and difficult to operate because, for example, a printer had to be installed before a typed document could be produced. However, in both cases the emerging innovations had additional functionality important to non-mainstream customers, which resulted in a fast growing adoption and new businesses that could refine the innovations until the performance matched those of the existing technologies. At this point and in spite of all the original opposition, the mainstream customer base typically abandoned existing technologies in favour of the emerging innovations causing disruption of the market and failure of the companies that was hooked into existing technologies [3-6].

Whilst TDI is useful in understanding disruption in retrospect, the impact of disruption is devastating and there is a need to develop such insights into disruption that it is possible to at least pre-empt full blown disruption that causes organizations to fail. This need is identified by scholars of disruptive innovations $[5,7,8]$ and some of the more recent work on the TDI such as Disruptive Strategy attempts to address this challenge by assisting existing organizations to develop strategies for growth $[5,9]$. However, we suggest that strategies that emerge from existing structures and value networks do not address the core challenges of disruption because it ignores the unpredictable behavior of low-profit adopter of a new technology with new functionalities. The investment, structures and legacy of organizations maintaining existing technology and functionality would still impede their capability to recognize and address disruptive innovations because they operate within an existing solution space. Existing value networks has as core focus solving the explicit need of customers using

\footnotetext{
${ }^{1}$ The recent work on Christensen's theory replaced the term technology with innovation.
} 
sustaining innovations based on existing solutions. Disruptive innovations also solve the customer needs, but not as effective and what ultimately lead to rapid adoption of disruptive innovations, is the additional functionality that the low-demand users find particularly useful. This additional functionality is mostly implicit, causing unpredictable customer behavior and emerges with adoption of the innovation. The purpose of our work is to identify this additional functionality (represented by performance attributes in TDI) through design thinking.

An example that illustrates this adoption behavior is a known scholar that used several typewriters in addition to being an early adopter of a personal computer. When explicitly asked how he would generate his scientific reports, he stated that he typed them. However, the additional functionality provided by word processing programs such as the ability to easily correct mistakes and store digital versions of documents that could serve as a basis for further work at a later stage, lured him into using a word processor as a primary writing tool. This was an implicit choice and was never explicitly stated; he never got rid of his typewriters even after word processors were the status quo. What this case illustrates is that it is precarious to focus on what customers explicitly express as they would probably state the status quo. Discussing disruption within the context of the key solution space functionality (i.e. writing in the age of typewriters) would not necessarily expose the implicit user needs fulfilled by the additional functionality of disruptive innovations. We therefore investigated alternative mechanisms that promote an explicit focus on unpredictable, implicit user behavior decoupled from the existing status quo and solution space. Design thinking, especially given recent developments within IS, represents such a paradigm [10]. Design thinking is a human-centered method that adopts the principle that 'innovation is made by humans for humans' and it focuses on understanding the human before thinking solution $[10,11]$, which is relevant to this study where focusing on existing solutions are part of the factors that were identified as contributing to disruption according to the TDI. We need to understand implicit customer needs and behavior without the solution space, and design thinking is appropriate for this as solution design only enter quite late into design thinking methodologies [12].

In this paper we report on initial work that use design thinking with the Theory of Disruptive Innovation in order to work towards an extended TDI. We propose that an understanding of implicit human needs and behavior due to additional performance attributes through design thinking could potentially expose why a disruptive innovation would be rapidly adopted. We used case-based scenario analysis as an evaluation method of the extended TDI. The remainder of this paper is structured as follows: the next sections provides background on TDI and design thinking, followed by section 4 that describes extending TDI with design thinking. Section 5 introduces cased-based scenario analysis as evaluation while the final section concludes.

\section{Theory of Disruptive Innovation}

The Theory of Disruptive Innovation (TDI) (Figure 1) is the core work of Christensen that focuses specifically on disruption caused by innovation, in contrast to the work on theories of digital innovation $[13,14]$. TDI as described originally uses hard disk 
performance to differentiate between sustaining and disruptive technologies given performance trajectories. The Y-axis depicts a performance attribute [4]. Sustaining technologies maintain a steady rate of improvement that gives customers better performance on existing attributes. In contrast, disruptive technologies originally perform much worse on the key existing attribute (so they have a low value on the Y-axis) but they provide a different set of attributes $[3,4,15]$. Christensen's theory subsequently states that mainstream customer adoption of a technology requires high performance on key attributes, and because companies are structured to prioritize delivery to mainstream customers (or are 'held captive' by their best customers), they disregard lowprofit customers that adopt low performance (potentially disruptive) technologies. A disruptive technology delivers on another set of attributes, which results in rapid adoption and subsequent growth with regards to performance on key performance attributes until it outperforms the existing sustaining technology. At this point the mainstream customer base abandons the existing technology and adopt the disruptive innovation resulting in the disruption of the company with the focus on the sustaining technology $[3,4,15]$.

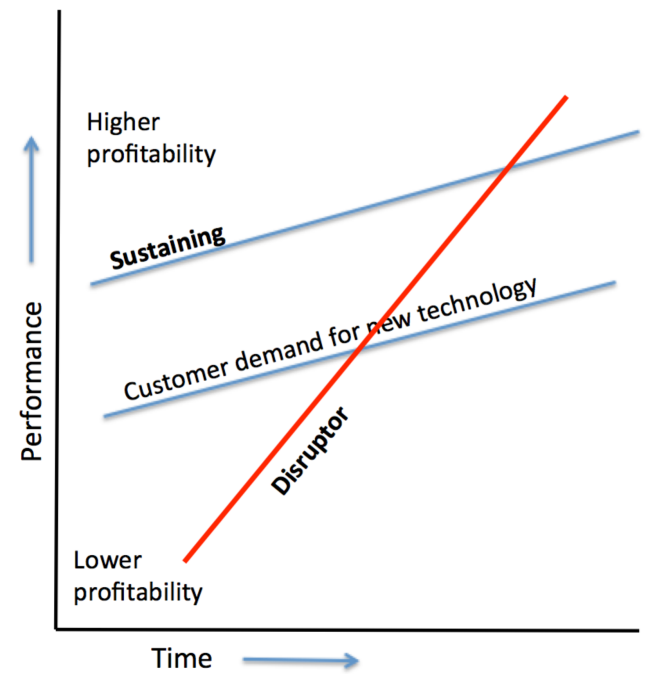

Figure 1: The Disruptive Innovation Model (based on versions from $[4,5,7,15]^{2}$ )

Later developments of TDI proposed refinements of the model as basis for a framework on disruptive innovation and the notion of technology is incorporated into innovation $[5,15]$. Most of this work favors strategies and frameworks for companies to detect and manage disruption, as well as mechanisms that could be used to structure or reorganize companies for optimum disruptive growth $[7,9,16]$. An observation of TDI is that the model used as basis for discussion (refer to Figure 1) is often

\footnotetext{
${ }^{2}$ Several versions of the model have been published $[4,5,7,15]$. Disruption is depicted linearly but with different gradients and even sometimes as an exponential curve. In some latter versions a 'different measure of performance' is depicted on a third axis (Fig 2-3 p.44 [7])
} 
ambiguous. The trajectories initially indicate technology growth but are afterwards used to describe customer adoption and demand. This might lead to misinterpretation, which is the bases of some of the critique against the theory [17]. Some critics claim that the theory is outdated or that the cases on which the theory was based, such as disk drives, are selective. Others claim that disruption itself is a vague concept not well defined, and that the theory does not provide a satisfactory explanation thereof [18-20]. However, proponents of TDI insist that it remains one of the basis theories that explains disruption even though it is acknowledged that refinements, specifically with regards to the capability to pre-empt disruption, are necessary $[8,21]$. The work reported on in this paper supports this research agenda and propose that understanding the human needs and behavior that drives adoption of an innovation is a significant indicator of its possibility to disrupt. We also propose that these needs are implicit and unpredictable, and therefore not readily distinguishable using established market analysis or requirements engineering (RE) techniques, especially ones that acknowledge an existing solution space or are bound to the status quo. Even though social goals or emotional goals are recognized and integrated into established RE techniques [22], these techniques have as basis approaches already working towards specific solutions. We adopt the position that any strategies that is based in existing solutions spaces and organizational structures do not address the core aspects of disruption. The focus on existing solutions and legacy functionality of existing organizations impedes their capability to recognize disruptive innovations with additional functionality that address implicit needs and behavior of emerging customers. We therefore do not attempt to augment ongoing work on DTI but propose a human centered approach that understands what human needs and behavior drive the rapid adoption of disruptive technologies. This is in line with the sentiment expressed by $\mathrm{Yu}$ and Hang [21] on future DTI research in that a question of 'tremendous interest' remains 'how to find emerging markets and understand the needs of new customers'. We identified design thinking as such a human centered approach because it emphasizes the understanding of human needs and behavior before proposing any solution.

\section{$3 \quad$ Design Thinking}

Design thinking refers to a process of creating artifacts through creation, prototyping, feedback and redesign. What distinguishes design thinking from other creative approaches, is its open-ended, often playful explorations "leading to solutions that avoid decisions and combines best possible choices" [12] (p.336). This is in contrast to science and engineering where the design process is precise and repeatable within strict scientific boundaries, focusing on finding solutions [23].

Different design thinking methods exist but all center on the user and understanding the user with empathy [10]. Gasparini [24] considers empathy as an emotional response (one feels what others feel) and cognitive response (one understand what others experience from their perspective). Both these types of empathy inform design thinking. An emotional feeling can be transformed into an attribute whereas certain approaches can be used to foster cognitive empathy of designers. He furthermore shows how cognitive empathy can be gained by using 'experience prototyping', for 
example to understand the everyday challenges and feelings of a person that use a wearable medical device. This understanding implies more than just what a user says, but focus more on user needs and what a user does. For example, the International Standards Organization proposes a methodology that uses design thinking as starting point for requirements discovering and specification [23]. Hehn et al. [25] also shows promising results from the combination of design thinking and RE approaches when creating innovative software systems. Given digitization and digital disruption several advocates of design thinking believes that the focus on the user and really understanding user needs and motivation within complex and messy environments at least provides some measures to address the associated challenges.

A well known design thinking method, the Stanford d.School Design Thinking method, starts with a comprehensive empathy mode that has as core goal establishing empathy with the user without any bias towards specific solutions [25]. The empathy mode then flows into a define mode that precisely describing a problem with insight and preserving the emotion and need but without a considering any solution [26]. An example of a result of the define mode is a set of user statements of the form [USER] needs to [User's NEED] because [INISGHT] [27]. After the define mode, the method proposes the ideate mode, which is the mode that for the first time considers solutions, but the intent is to suggest "radical design alternatives" by "going wide" rather than focusing on a specific solution, followed by prototyping and testing modes. However, in contrast to known development methods, the prototyping and testing modes has as main purpose understanding and refining user needs, and not as such providing solutions. As stated, we believe that understanding user needs without any presupposed and existing solutions is core towards understanding disruption because user needs are the driving force for the adoption of emerging disruptive innovations.

\section{Design Thinking and The Theory of Disruptive Innovation}

By focusing on additional functionality of disruptive innovations, we complement the Theory of Disruptive Innovation in two ways: 1) Extending the performance attribute (PA) that serves as the basis of the theory by adding functionality performance values; and 2) using design thinking to determine existing and additional functionality performance values through the identification of implicit and explicit user needs.

We propose this complement as the first step to the development of a Theory of Disruptive Innovation that is pre-emptive in nature, and not just explanatory.

\subsection{Extending the Performance Attribute of the Theory of Disruptive Innovation}

As discussed, performance serves as the basis of TDI. The performance attribute (PA) is depicted on the Y-axis of all the models of the theory as rendered in Figure 1 and is used to differentiate between sustaining and disruptive innovations, as well as the adoption behavior of mainstream or emerging customers. The current applications of the theory focus on assisting existing companies with identifying and managing innovations in order to sustain growth. We claim that strategies within existing para- 
digms and solutions impede the capability to recognize and address disruptive innovations because the additional functionality that the low-demand users find particularly useful emerges with the rapid adoption of the innovation.

Even though the performance attribute (PA) is key to DTI, limited in-depth investigations into what is meant with performance exist. When TDI centered around a single technology such as disk drives, performance was disk drive capacity [3]. However, when the innovation is Uber, performance is vaguely defined [15]. We argue that the vague meaning of this performance attribute leads to most disagreements about the nature of disruption, the value of the theory or critique against the theory, as well as the capability to pre-empt disruption.

A scrutiny of the PA discussions indicates that the performance is always mentioned within context of a functionality that responds to a specific user need. A disruptive innovation is described as an innovation that provides additional functionality (or as described as 'different measures of performance' (Fig 2-3 p.44 [7]). We therefore propose that the Performance Attribute (PA) implies a sum of a set of basis functionality performance values $(f)$ and the sum of a set of additional functionality performance values $\left(f^{\prime}\right): P A \rightarrow\left\{f_{1}+f_{2}+, \ldots,+f_{n}\right\}+\left\{f_{1}^{\prime}+f_{2}^{\prime}, \ldots,+f_{m}^{\prime}\right\}$

A functionality performance value is defined as a response to a user need for example the speed-of-typing. When the innovation is sustaining, there would necessarily be no or few additional functionality performance for example $P A \rightarrow\left\{f_{1}+f_{2}\right\}$ where $f_{1}$ may be the speed of typing and $f_{2}$ the size of the typewriter and when both have high values, the position on the Y-axis is high). When an innovation is disruptive, there are several additional functionality performance values $\left(f^{\prime}\right)$. Originally the sum of the values would be low as the innovation is not mature, but the combination of values are attractive enough for adoption by a large community of users. The innovation necessarily see rapid adoption from the community of users that find the additional functionality attractive resulting in PA rapidly growing as the sum of the different additional functionality performance values each increase until the determining functionalities are of sufficient value to disrupt existing innovations.

In order to determine functionality performance values (both basic and additional), it is necessary to understand user needs, and therefore we extend the performance attribute of TDI with design thinking as discussed in the next section.

\subsection{Determining Functionality Performance Values through Design Thinking}

The predominant publications on TDI starts with discussions on the difference between sustaining and disruptive innovations by referring to its performance, and subsequently discuss customer adoption of these innovations, including how additional functionality or different performance attributes lead to disruptive innovations. Innovator's Solution states that being more predictable does not "entail learning to predict what individuals might do. Rather, it comes from understanding the forces that act upon the individuals involved in building businesses". The remainder of the work then focuses on individuals within businesses and presents several strategies for companies to innovate and grow based on the theory. 
We propose that existing company structures that are representative of a specific solution space or paradigm prohibits its participants to effectively detect the different disruptive customer behavior that are the result of additional functionality of disruptive innovations. We suggest that the additional, often implicit and unspoken user needs that disruptive innovations address are core to understanding, and therefore preempting, disruptive innovations. Because these user needs are implicit and unknown, we employ solution independent design thinking that focus on thoroughly understanding the user through empathy. Using the extended Performance Attribute in the previous section

$\left(P A \rightarrow\left\{f_{1}+f_{2}+, \ldots,+f_{n}\right\}+\left\{f_{1}^{\prime}+f_{2}^{\prime}, \ldots,+f_{m}^{\prime}\right\}\right)$ we therefore propose the following steps:

1) Determine the context of the innovation and determine the basis functionality of the innovation (e.g. typing).

2) Determine the set of basis functionality performance values $(f)$ (e.g. speed of typing).

3) Establish the basis PA as $P A \rightarrow\left\{f_{1}+f_{2}+, \ldots,+f_{n}\right\}$

4) Using the basis functionality of the innovation as well as basis functionality performance values (steps 1 and 2), identify as many as possible alternative innovations that address or could possibly address the basis functionality (that would typically be low on the PA of step 3 ).

5) Establish a solution independent design thinking team (the team should not in any way be proponents of existing sustaining innovations, therefore should not belong to organizations that support or maintain sustaining solutions).

6) Use design thinking empathy to 'deeply' understand the needs and behavior (both explicit and implicit) of the early adopters and users of the alternative innovations as well as the forces and paradigms these users embrace. This could be in the form of the d-school define mode namely a set of user statements of the form [USER] needs to [User's NEED] because [INISGHT] [27].

7) Determine the initial set of additional functionality performance values $\left(f^{\prime}\right)$ in order to evaluate the disruptive innovation through: $\left.P A \rightarrow\left\{f_{1}+f_{2}+, \ldots,+f_{n}\right\}+\left\{f_{1}^{\prime}+f_{2}^{\prime}, \ldots,+f_{m}^{\prime}\right\}\right)$.

8) Use the additional design thinking methods and steps (e.g. prototyping) to refine the user understanding, as well as propose radical and creative innovations (independent from existing solutions).

9) Refine the set of additional functionality performance values $\left(f^{\prime}\right)$ in order to evaluate the disruptive innovation through $P A \rightarrow\left\{f_{1}+f_{2}+, \ldots,+f_{n}\right\}+$ $\left.\left\{f_{1}^{\prime}+f_{2}^{\prime}, \ldots,+f_{m}^{\prime}\right\}\right)$.

10) Feed the results back into the proposed strategies of the TDI for company growth and development (e.g. decisions of how such proposed innovations should be explored and developed (in-house or spin-off)).

\section{Evaluation: Case-based Scenario Analysis}

As an initial evaluation of the proposed extended TDI for this paper, we adopted casebased scenario analysis. Scenario analysis is an approach that investigates alternative 
futures based on storyline-driven modeling [28, 29]. Such scenario analysis has been adopted in research that attempts to understand complex social contexts, especially where implicit knowledge has an impact such as in our research. We used the extended TDI as the storyline for the scenario analysis with higher education as case.

Higher education (HE) is defined as education beyond secondary level, usually provided by a higher education institution (HEI) such as a college or a university [30]. Given the emergence of several alternative mechanisms for higher education such as online courses and MOOCs [31], we initiated an investigation into disruptive innovation within the context of HE. Several discussions on whether MOOCs are potential disruptors for HEI abounds [32-35], and for this study we take the position that MOOCs provide additional functionality such as on-demand specific training when required by the changing nature of the workplace, as well as accessibility, customizability and affordability in contrast with classical HEI structures [34]. In the modern workplace claims are often made that a degree is already outdated when it is bestowed and that alternative life-long-learning training technologies will replace HEIs [36]. We used interviews with diverse role-players including middle management as well as enrolled students at HEIs to collect information and did a thematic analysis on the information acquired. We specifically investigated how the provision of higher education by HEIs differ from the alternative MOOC education mechanisms, and we identified accredited certification (degrees or diplomas) as the main differentiator, followed by structured learning environments (i.e. face-to-face lectures at specific venues at specific times and an established curriculum). For our scenario analysis we executed Steps 1-7 as Steps 8-10 represent design thinking iterations for the refinement of user needs analysis and proposed innovations. We executed Steps 1-7 as follow:

1) The context of the innovation is the provision of $H E$.

2) The basis functionality performance values $(f)$ for this scenario analysis was identified to be accredited certification (degrees or diplomas) and structured learning environments.

3) $\mathrm{PA}=$ provision of $\mathrm{HE} \rightarrow f_{1}$ (providing accredited certification) + $f_{2}$ (providing structured learning environments)

4) For the scope of this paper, the scenario analysis will only consider MOOCs as an alternative possible disruptive innovation. MOOCs measure low on the PA of step 2 namely the provision of accredited certification and structured learning environments such as face-to-face lectures at specific locations and times.

5) An initial execution of Step 5 was done by recruiting design thinking students. However, during the team brief we realized that these students (as participants in the education of an established HEI) are adopters of the 'existing solution' and their evaluation of MOOCs was therefore biased; they believed that a degree is necessary the solution to future job security in contrast with the HEI disruption sentiments. This supported our position that adopters of existing solutions do not consider the potential of disruptive innovations, and we rephrased step 5 to be the establishment of a solution independent design thinking team. Limited opportunities within the scope of this study prohibited the establishment of a completely independent team, and we assigned a design thinking trainer knowledgeable about MOOCs and their possibilities to do an initial execution of Step 6. 
6) An initial empathy investigation into the needs of users that adopt MOOCs identified a number of user needs. The main reason why users enter HE is to be employable, and even though the mainstream advocates for employability still emphasize degrees, several additional voices emerge that emphasize alternative qualifications [37]. The exorbitant cost of $\mathrm{HE}$ is a huge challenge, and several people feel excluded and often angry because of the entry barrier. In addition, students can seldom work to support studies because they have to move to close proximity of a campus and the structured learning environment (i.e. face-to-face lectures). The accessibility of MOOCs as well as the freedom to learn wherever and whenever possible make them an attractive alternative to HE, however, uncertainty about the value of $\mathrm{MOOC}$ and online certifications still provide a barrier. The flexible course structure where users could choose the most relevant courses are particularly attractive. The delivery mechanism that enable users to go back to video lectures assists with better learning because core concepts can be revisited. Users realize that continuous education and up-skilling will be a prerequisite to the future workplace and for such requirements, MOOCs are a key resource. Users do not necessarily complete courses, but use 'high value' MOOCs to obtain the skills necessary to better perform at existing jobs.

7) An initial set of additional functionality performance values $\left(f^{\prime}\right)$ therefore include: 1) providing ease of access to learning; 2) providing flexible course structures; 3 ) providing flexible learning environments (that support the freedom to learn wherever and whenever possible); 4) affordability; and 5) provide flexible delivery mechanisms of course content (for instance through videos).

The additional functionalities provided give insight into the reasons why users adopt MOOCs. The structured learning environments that are regarded as an advantage of existing HEI are actually considered a barrier by most online education adopters. Given the movement of MOOCs to provide acceptable and competitive accreditation mechanisms, which is one of the most valuable performance attributes determinants of HE, it is possible to argue that online education might possibly disrupt existing higher education, and existing HEIs could consider alternative mechanisms that support the identified additional functionalities that encourage user adoption.

\section{Conclusion}

In this paper we report on initial work to extend the Theory of Disruptive Innovation (TDI) using design thinking as a first step to identify additional functionality represented as performance attributes in order to pre-empt disruption. Our complement to the theory includes an extension of the performance attributes of the TDI in addition to a design thinking method that could be used to establish the often-implicit user needs and behavior that support the adoption of disruptive innovations. Further research includes refinement of the performance attribute and functionality performance values, as well as a refinement and extensive evaluation of the proposed design thinking method. The ability of the theory to better understand digital disruption would assist organizations to mediate and pre-empt the impact thereof. 


\section{$7 \quad$ References}

1. Osborne, D.: The moment it all went wrong for Kodak, http://www.independent.co.uk/news/business/analysis-and-features/the-moment-it-all-wentwrong-for-kodak-6292212.html, (2012).

2. Smith Corona Corp.: History of Smith Corona Corp., https://www.referenceforbusiness.com/history2/50/Smith-Corona-Corp.html.

3. Bower, J.L., Christensen, C.M.: Disruptive Technologies: Catching the Wave. Harvard Business Review. (1995).

4. Christensen, C.M.: The innovator's dilemma: when new technologies cause great firms to fail. Harvard Business School Press, Boston, Mass (1997).

5. Christensen, C.M., McDonald, R., Altman, E.J., Palmer, J.: Disruptive Innovation: Intellectual History and Future Paths. Harvard Business School (2016).

6. Clayton Christensen: Disruptive Innovation and Catalytic Change in Higher Education. Forum for the Future of Higher Education. (2008).

7. Christensen, C.M., Raynor, M.E.: The innovator's solution: creating and sustaining successful growth. Harvard Business School Press, Boston, Mass (2003).

8. Christensen, C.M.: The Ongoing Process of Building a Theory of Disruption. Journal of Product Innovation Management. 23, 39-55 (2006). https://doi.org/10.1111/j.15405885.2005.00180.x.

9. Christensen, C.: Online Course: Clayton Christensen Disruptive Strategy | HBX, https://hbx.hbs.edu/courses/disruptive-strategy/.

10.Brenner, W., Uebernickel, F., Abrell, T.: Design Thinking as Mindset, Process, and Toolbox. In: Brenner, W. and Uebernickel, F. (eds.) Design Thinking for Innovation. pp. 321. Springer International Publishing, Cham (2016). https://doi.org/10.1007/978-3-31926100-3 1.

11.Nigel Cross: Design Thinking: Understanding How.

12.Razzouk, R., Shute, V.: What Is Design Thinking and Why Is It Important? Review of Educational Research. 82, 330-348 (2012). https://doi.org/10.3102/0034654312457429.

13.Nambisan, S., Lyytinen, K., Majchrzak, A., Song, M.: Digital Innovation Management: Reinventing Innovation Management Research in a Digital World. MIS Quarterly. (2016).

14.Tuomi, I.: Theories of Innovation: Change and Meaning in the Age of the Internet. Oxford University Press, Inc., New York, NY, USA (2002).

15.Christensen, C.M., Raynor, M.E., McDonald, R.: What Is Disruptive Innovation?, https://hbr.org/2015/12/what-is-disruptive-innovation, (2015).

16.Schmidt, G.M., Druehl, C.T.: When is a disruptive innovation disruptive? Journal of product innovation management. 25, 347-369 (2008).

17.Fitzgerald, J.: Clay Christensen explains, defends 'disruptive innovation' - The Boston Globe, https://www.bostonglobe.com/business/2015/10/24/clay-christensen-explainsdefends-disruptive-innovation/fmYOKIJXOSPPMquj8HQM1O/story.html, (2015).

18.King, A.A., Baatartogtokh, B.: How useful is the theory of disruptive innovation? MIT Sloan Management Review. 57, 77 (2015).

19.Markides, C.: Disruptive innovation: In need of better theory. Journal of product innovation management. 23, 19-25 (2006). 
20.Geller, L.W.: Howard $\mathrm{Yu}$ Disrupts Disruptive Innovation, https://www.strategybusiness.com/article/Howard-Yu-Disrupts-Disruptive-Innovation?gko=f75fc, (2017).

21.Yu, D., Hang, C.C.: A Reflective Review of Disruptive Innovation Theory: A Reflective Review of Disruptive Innovation Theory. International Journal of Management Reviews. 12, 435-452 (2010). https://doi.org/10.1111/j.1468-2370.2009.00272.x.

22.Curumsing, M.K., Fernando, N., Abdelrazek, M., Vasa, R., Mouzakis, K., Grundy, J.: Emotion-oriented requirements engineering: A case study in developing a smart home system for the elderly. Journal of Systems and Software. 147, 215-229 (2019). https://doi.org/10.1016/j.jss.2018.06.077.

23.Shneiderman, B.: The New ABCs of Research: Achieving Breakthrough Collaborations. Oxford University Press (2016).

24.Gasparini, A.A.: Perspective and Use of Empathy in Design Thinking. 6.

25.Both, T., Baggereor, D.: The D.School Bootcamp Bootleg, https://dschool.stanford.edu/resources/the-bootcamp-bootleg, (2017).

26.Stanford d.school, https://dschool.stanford.edu/.

27.Stanford d.school: POV Madlibs: 3, https://dschoolold.stanford.edu/groups/k12/revisions/22e39/3/.

28.Garb, Y., Pulver, S., VanDeveer, S.D.: Scenarios in society, society in scenarios: toward a social scientific analysis of storyline-driven environmental modeling. Environmental Research Letters. 3, 045015 (2008). https://doi.org/10.1088/1748-9326/3/4/045015.

29.Beese, J., Haki, M.K., Aier, S., Winter, R.: Simulation-Based Research in Information Systems: Epistemic Implications and a Review of the Status Quo. Business \& Information Systems Engineering. (2018). https://doi.org/10.1007/s12599-018-0529-1.

30.Definition of HIGHER EDUCATION, https://www.merriamwebster.com/dictionary/higher+education.

31.What is a MOOC?, https://about.futurelearn.com/blog/what-is-a-mooc-futurelearn.

32.Stepan, A.: Massive Open Online Courses (MOOC) Disruptive Impact on Higher Education, http://summit.sfu.ca/system/files/iritems1/13085/EMBA\%25202013\%2520Anita\%2520Step an.pdf.

33.Flynn, J.T.: Moocs: Disruptive Innovation and the Future of Higher Education. Christian Education Journal: Research on Educational Ministry. 10, 149-162 (2013). https://doi.org/10.1177/073989131301000112.

34.Christensen, G., Steinmetz, A., Alcorn, B., Bennett, A., Woods, D., Emanuel, E.: The MOOC Phenomenon: Who Takes Massive Open Online Courses and Why? SSRN. 25 (2013).

35.Pappano, L.: The Year of the MOOC, (2012).

36.Blank, S.: College Degrees Are Outdated For Today's Uncertain Work Environment, https://www.businessinsider.com/college-and-business-will-never-be-the-same-2011-2, (2011).

37.Businesstech: These 10 jobs are the hardest to fill in South Africa, https://businesstech.co.za/news/business/283662/these-10-jobs-are-the-hardest-to-fill-insouth-africa/, (2018). 